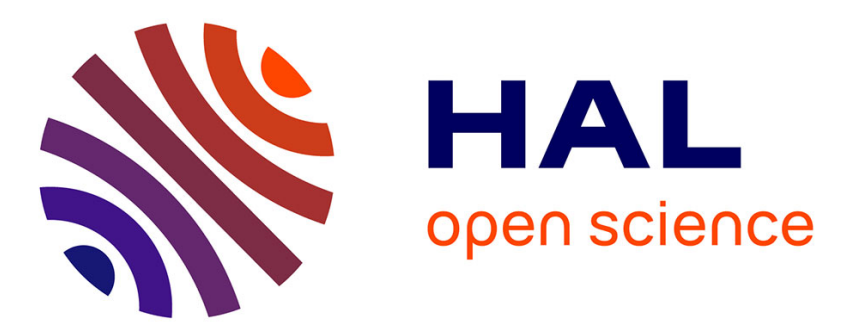

\title{
On the mechanical interplay between intra- and inter-synchronization during collective cell migration : a numerical investigation
}

\author{
Rachele Allena, Denis Aubry, J. Sharpe
}

\section{- To cite this version:}

Rachele Allena, Denis Aubry, J. Sharpe. On the mechanical interplay between intra- and intersynchronization during collective cell migration: a numerical investigation. Bulletin of Mathematical Biology, 2013, 75 (12), pp.2575-99. 10.1007/s11538-013-9908-4 . hal-01068664

\section{HAL Id: hal-01068664 https://hal.science/hal-01068664}

Submitted on 14 Oct 2014

HAL is a multi-disciplinary open access archive for the deposit and dissemination of scientific research documents, whether they are published or not. The documents may come from teaching and research institutions in France or abroad, or from public or private research centers.
L'archive ouverte pluridisciplinaire HAL, est destinée au dépôt et à la diffusion de documents scientifiques de niveau recherche, publiés ou non, émanant des établissements d'enseignement et de recherche français ou étrangers, des laboratoires publics ou privés. 


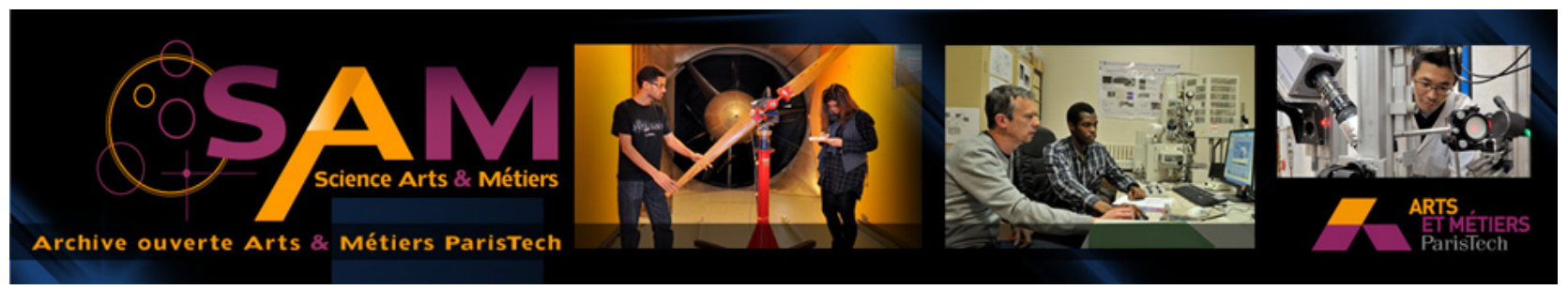

Science Arts \& Métiers (SAM)

is an open access repository that collects the work of Arts et Métiers ParisTech researchers and makes it freely available over the web where possible.

This is an author-deposited version published in: http://sam.ensam.eu

Handle ID: .http://hdl.handle.net/10985/8624

\section{To cite this version :}

Rachele ALLENA, Denis AUBRY, James SHARPE - On the mechanical interplay between intraand inter-synchronization during collective cell migration : a numerical investigation - Bulletin of Mathematical Biology - Vol. 75, n¹2, p.2575-99 - 2013 


\title{
On the Mechanical Interplay Between Intra- and Inter-Synchronization During Collective Cell Migration: A Numerical Investigation
}

\author{
R. Allena $\cdot$ D. Aubry $\cdot$ J. Sharpe
}

\begin{abstract}
Collective cell migration is a fundamental process that takes place during several biological phenomena such as embryogenesis, immunity response, and tumorogenesis, but the mechanisms that regulate it are still unclear. Similarly to collective animal behavior, cells receive feedbacks in space and time, which control the direction of the migration and the synergy between the cells of the population, respectively. While in single cell migration intra-synchronization (i.e. the synchronization between the protrusion-contraction movement of the cell and the adhesion forces exerted by the cell to move forward) is a sufficient condition for an efficient migration, in collective cell migration the cells must communicate and coordinate their movement between each other in order to be as efficient as possible (i.e. intersynchronization). Here, we propose a 2D mechanical model of a cell population, which is described as a continuum with embedded discrete cells with or without motility phenotype. The decomposition of the deformation gradient is employed to reproduce the cyclic active strains of each single cell (i.e. protrusion and contraction). We explore different modes of collective migration to investigate the mechanical interplay between intra- and inter-synchronization. The main objective of the paper is to evaluate the efficiency of the cell population in terms of covered distance and how the
\end{abstract}

R. Allena $(\varangle) \cdot J$. Sharpe

EMBL-CRG Systems Biology Research Unit, Centre for Genomic Regulation (CRG), UPF,

Barcelona, Spain

e-mail: rachele.allena@ensam.eu

R. Allena

Arts et Metiers ParisTech, LBM, 151 Bd de l'hopital, 75013 Paris, France

D. Aubry

Laboratoire MSSMat UMR CNRS 8579, Ecole Centrale Paris, 92295 Châtenay-Malabry, France 
stress distribution inside the cohort and the single cells may in turn provide insights regarding such efficiency.

Keywords Collective cell migration · Intra- and inter-synchronization · Continuum mechanics

\section{Introduction}

Cells can move individually or collectively. The number of migrating cells may vary from a few cells (i.e. egg chamber development in Drosophila) to hundreds (i.e. lateral line primordium in Zebrafish) or hundreds of thousands of cells (i.e. slug development in Dyctyostelium).

Although key aspects of single cell migration such as the control of protrusive activity, shape generation and interaction between the cell and the extra cellular matrix (ECM) are fairly well understood (Friedl and Gilmour 2009), the mechanisms that regulate collective cell migration are less clear.

As in single cell migration (Allena and Aubry 2012), the movement of the cells inside the population is triggered by a tight synchronization between shape changes and adhesion forces inside the cell (intra-synchronization), which results in a cyclic four (Flaherty et al. 2007) or five (Meili et al. 2010; Sheetz et al. 1999) steps process.

Nevertheless, contrarily to single cell migration, in collective cell migration the acquirement of a motility behavior by each cell does not guarantee the correct movement of the population and therefore it is not a sufficient condition. In fact, the cells inside the cohort need to communicate and to coordinate their movement with their neighbors in order to be as efficient as possible. Thus, as in collective animal behavior (Sumpter 2006), in collective cell migration we may observe positive feedbacks in space and time. Positive feedback in space builds up a collective pattern by transforming the isolated behavior of a single cell into a mass of similar behaviors. Positive feedback in time or inter-synchronization consists in small adjustments by individual cells of their own migration frequency toward that of some local average. The coupling between positive feedback in space and inter-synchronization results in a spatio-temporal wave, which regulates the collective movement and, although so far little explored, it may play a fundamental role in determining the migratory efficiency of the population.

Actually, individual cells can migrate in large populations by closely interacting over long distances or migrating as epithelial sheets where neighbor connections do not change significantly (Weijer 2009). While in the former case cells move together in a manner similar to that of single cells, in the latter case cells remain linked both physically and functionally during the movement (Friedl and Gilmour 2009). Cellcell junctions are maintained through adherens junctions proteins, desmosomal proteins, and integrins (Friedl and Gilmour 2009; Ilina and Friedl 2009), which prevent the formation of gaps between the cells (Anand et al. 2007). These interactions limit the movement of the cells within the layer and restrict any cellular rearrangement.

Finally, it is still unclear whether all the cells or only the leader cells of the population participate to the collective migration. In fact, the distinction between leader 
(located at the free boundary) and follower (located in the cell cohort) cells has been thought to be the main feature of collective cell migration (Friedl and Gilmour 2009) with the former exerting larger traction forces than the latter (Trepat et al. 2009). Nevertheless, further studies have shown that both cells actually generate protrusions to coordinate the forward movement (Farooqui and Fenteany 2005; Fenteany et al. 2000; Tambe et al. 2011) and that the cell velocity is inversely proportional to the distance from the free boundary (Farooqui and Fenteany 2005).

\subsection{Numerical Models of Collective Cell Migration}

Numerical simulations are a powerful approach to test hypotheses about biological phenomena. For collective cell migration, we can distinguish between two categories of computational models: (i) the agent-based models (AGMs) and (ii) the continuum models (CMs). AGMs simulate the activity and the interactions of cells within a population and assess their influence on the global system by taking into account the rate of cell division, the cell proliferation, the adhesion between the cells and the substrate, the deformation energy, and the stochastic behavior of the cellular collective (Graner and Glazier 1992; Szabo et al. 2006; Vedel et al. 2013; Vicsek et al. 1995; Yamao et al. 2011).

CMs may be subdivided into two sub-categories. On the one hand, the model may be based on conservation equations of the cell density and of a mitosis-regulating chemical agent (Sherratt and Murray 1990, 1991). On the other hand, the cell layer may be represented as an incompressible fluid whose configuration is described by the density of cells and the velocity includes a growth term due to proliferation and apoptosis. Additionally, the adhesion forces of the layer sheet to the substrate and the stresses within the population are considered (Arciero et al. 2011).

A few models (McLennan et al. 2012; Yamao et al. 2011) describe the collective migration focusing on the movement of the neural crest, which occurs in the absence of extracellular signals.

Further studies have analyzed collective migration during the wound healing process. They have considered it as a free boundary problem and have taken into account the influence of physiological electric field on the wound closure in corneal wound healing (Gaffney et al. 1999), tumor growth (Chen and Friedman 2000), or ischemic dermal wounds (Xue et al. 2009).

Finally, we mention the works of Maini et al. (2004) and Serra-Picamal et al. (2012), which combine numerical and experimental approaches and may be of major interest for the present paper. Maini et al. (2004) have performed a 'wound healing' assay and have validated a model to assess the relationship between cell motility and proliferation. The authors have found that after a short period of time the frontal edge of the cell population moves as a traveling wave at constant speed.

Serra-Picamal et al. (2012) have discovered a mechanical wave that progressively spans a micropatterned epithelial monolayer across the cell-cell junctions and creates differentials of mechanical stress that trigger the migration of the population. Additionally, they have analyzed such a scenario through a 1D model in which the cells of the monolayer are represented by springs connected in series and are able to generate propelling forces that can be transmitted to the neighbor cells (elastic forces) or to the underneath gel substrate (viscous forces). 


\subsection{Objective of This Work}

In the present paper, we propose a two-dimensional (2D) finite element model to simulate the collective migration of a cell population, which is based on the following hypotheses:

- the cohort is represented as a continuum with embedded discrete cells, which may have or not a motility phenotype. The cohort includes approximately hundred cells;

- as in previous works (Borisy and Svitkina 2000; Carlier and Pantaloni 1997; Condeelis 1993; Mogilner and Rubinstein 2005; Theriot and Mitchison 1991), the oscillating protrusion-contraction movement of the motile cells is assumed to be controlled by the cyclic polymerization-depolymerization process of the actin network inside the cytoskeleton;

- the decomposition of the deformation gradient (Allena et al. 2010; Lubarda 2004) is employed to take into account the active elementary deformations undergone by the motile cells (i.e. protrusion and contraction) as well as the elastic deformations generated by the interaction of the cells with the ECM (Allena 2013; Allena and Aubry 2012);

- large deformations of the motile cells are considered and the cells are able to form one pseudopod at a time at their leading edge (Allena and Aubry 2012);

- inside each motile cell the intra-synchronization between the active strains and the adhesion forces to the ECM is described (Allena 2013; Allena and Aubry 2012);

- finally, different modes of collective migration are investigated. Each one of these modes is triggered by a specific inter-synchronization between the cells resulting in different scenarios.

As in previous models of single cell migration (Carlsson and Sept 2008; Flaherty et al. 2007; Rubinstein et al. 2005; Sakamoto et al. 2011; Taber et al. 2011), we have decided here to only focus on the mechanical aspects of the phenomenon. Such a choice is motivated by the following reasons. First, the molecular, genetic, and chemical environments may vary according to the biological model one considers. However, the cell and the population movements are still governed by the Newton's law of motion (Murray 2003), which provides insights on the admissibility of given movements. Second, to unveil the forces and the strains resulting from the collective migration, we need to simulate the physics of the process, so that we are able to detect those constraints, which lead (or not) to an efficient migration of the population. In order to achieve such a goal, different scenarios must be tested to evaluate the mechanical interplay between intra- and inter-synchronization and to conclude whether such configurations are realistic or not.

\section{The Model}

In this section we present the general framework of the model. We first describe the 2D geometry of the cell cohort and of its constituent cells. Subsequently, we define the constitutive law for each of the component of the population, together with the 


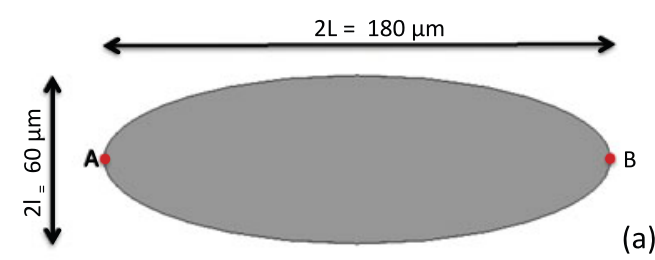

$A=$ stern

$B=$ bow

(a)
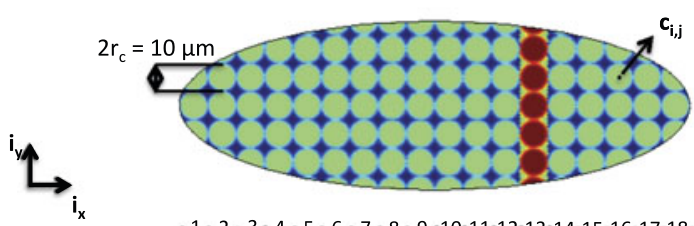

$\square \mathrm{r}(\mathrm{i})$

$\square \operatorname{cell}(i, j)$

$\square \mathrm{ECM}$

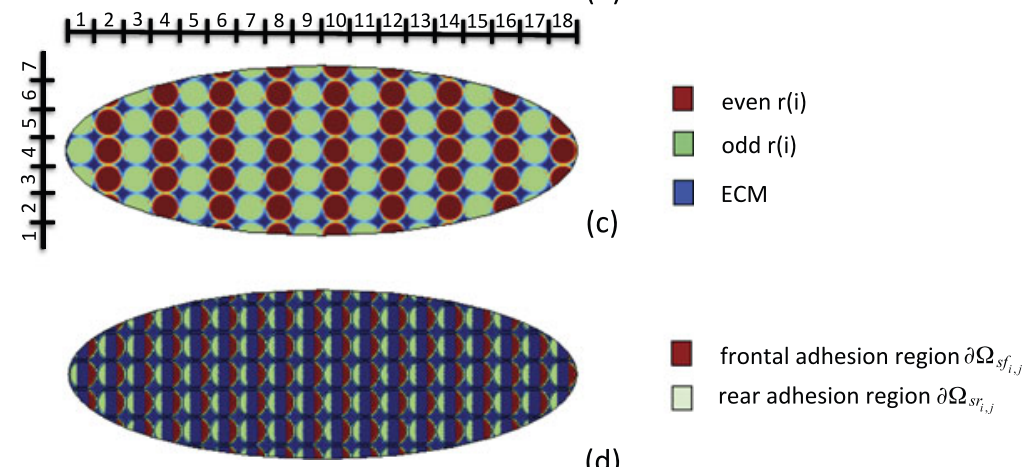

(d)

Fig. 1 (a) Geometry of the cell population. (b) Representation of the cell network $h_{n}(\boldsymbol{p})$. Each cell $c(i, j)$ (green) has a circular shape with radius $r_{c}$ and centre $c_{i, j}$. (c) The ellipse is divided in cell rows $r(i)$ which are numbered from the stern to the bow of the ellipse (in red the even rows, in green the odd rows). The ECM (blue) fills the interstices between the cells. (d) Representation of the initial frontal (red) and rear (green) adhesion surfaces (Color figure online)

active deformations (protrusion and contraction) that take place during the migration process. Finally, we describe the intra- and the inter-synchronizations according to the different modes of migration adopted by the cells aggregate.

\subsection{Geometry of the Cell Population}

In the orthogonal frame $\left(\boldsymbol{i}_{x}, \boldsymbol{i}_{y}\right)$, the cells cohort has been modeled as a continuum and approximated by an ellipse with semi-axes $L$ and $l$ (Fig. 1a) free at its outer boundaries. The ellipse includes the cell network $\Omega_{n}$, which is described through a characteristic function $h_{n}(\boldsymbol{p})$ (Eq. (9)) and is constituted by 106 cells. The cells are in contact with each other and embedded in the extracellular matrix (ECM) $\Omega_{\mathrm{ECM}}$, identified by the characteristic function $h_{\mathrm{ECM}}(\boldsymbol{p})$ (Eq. (10)). Inside the cell network, we can distinguish between the active $\left(\Omega_{a, k}\right)$ and the quiescent $\left(\Omega_{q, k}\right)$ cells domains, which are represented through two characteristic functions $h_{a, k}(\boldsymbol{p})$ and $h_{q, k}(\boldsymbol{p})$ (Sect. 2.3.2). The number of active cells inside the population may vary according to the mode of migration adopted by the cohort (the underscript ' $k$ ' indicates such a mode (see Sect. 2.3.2)). Consequently, the quiescent cell domain $\Omega_{q, k}$ is the complementary of $\Omega_{a, k}$ with respect to $\Omega_{n}$. 
Each cell $c(i, j)$ inside the cohort has an initial circular shape (Fig. 1b, Eq. (12)) with radius $r_{c}$ and centre $c_{i, j}\left(c_{i, j_{x}}, c_{i, j_{y}}\right)$, where the indices $i$ and $j$ indicate the position of the cell along the major and minor axes of the ellipse, respectively (Fig. 1c, Eq. (11)). For each cell, a frontal $\left(\partial \Omega_{s f_{i, j}}\right)$ and a rear $\left(\partial \Omega_{s r_{i, j}}\right)$ adhesion regions are defined through two characteristic functions $h_{s f_{i, j}}$ and $h_{s r_{i, j}}$, respectively (Eq. (13)), which allow the cell to adhere to the ECM. Here, we assume that the motile cells migrate along the horizontal axis $\boldsymbol{i}_{x}$. Additionally, the ellipse is divided into cell rows $r(i)$ (Eq. (14)), which are numbered, similarly to the single cells, from the stern (left) to the bow (right) of the ellipse (Fig. 1b).

\subsection{Constitutive Model and Active Deformations}

As mentioned in the previous section, three main regions constitute the mechanical system and each one of them has a specific constitutive behavior.

The first region contains the motile cells $\left(\Omega_{a, k}\right)$, which actively participate to the migration process by cyclically protruding and contracting. It has been observed that a migrating cell is in general stiffer than a quiescent one (Wagh et al. 2008) and presents a gradual but significant decrease in stiffness from the front to the rear of the lamellipodia in agreement with the actin density profile (Ilina and Friedl 2009). As in our previous work (Allena 2013; Allena and Aubry 2012), we use a 2D generalized viscoelastic Maxwell model to describe the behavior of each cell which is constituted by two phases: (i) a solid-like phase (the actin filaments) where the active strains take place and (ii) a fluid-like phase, which includes some particles (the organelles, fluidelastic) embedded into a fluid (cytoplasm, fluid-viscous). Thus, the active cells show a solid Young's modulus $E_{a, s e}$ larger than the fluid-elastic Young's modulus $E_{a, f e}$ (Appendix A.2).

The second region includes the inactive (or quiescent) cells $\left(\Omega_{q, k}\right)$ that follow the movement because of their connection to the active migrating cells. As for the active cells, a generalized viscoelastic 2D Maxwell model is used to reproduce their mechanical behavior. Nevertheless, the active strains (i.e. the actin filaments polymerization) do not occur in these cells, which are believed to influence the stiffness of the cell. Thus, the Young modulus $E_{q, s e}$ of the solid elastic phase is considered to be much lower than $E_{a, s e}$ (Soofi et al. 2009).

Finally, the third region is the one of the extracellular matrix $\left(\Omega_{\mathrm{ECM}}\right)$ that fills the interstices between the cells (Fig. 1b). The ECM is assumed to be a viscoelastic material, with Young modulus and viscosity $E_{\mathrm{ECM}}$ and $\mu_{\mathrm{ECM}}$ respectively.

Let $\rho$ be the cells density, $\boldsymbol{a}$ the acceleration, $\sigma$ the Cauchy stress, $\boldsymbol{F}$ the deformation gradient and $J$ its determinant, then since we consider the inertial effects (Gracheva and Othmer 2004), the Newton law applied to the continuum with respect to the initial configuration $\boldsymbol{p}$ is given by

$$
\rho \boldsymbol{a}=\operatorname{Div}_{p}\left(J \sigma \boldsymbol{F}^{-T}\right)+\boldsymbol{f}_{\mathrm{adh}}
$$

with $\operatorname{Div}_{p}$ the divergence with respect to the initial position, $A^{-T}$ the inverse transpose of the matrix $\boldsymbol{A}$ (Holzapfel 2000; Taber 2004) and $\boldsymbol{f}_{\text {adh }}$ the adhesion forces between the cell and the substrate, which will be described in the next section (Sect. 2.3.1). 
The protrusion and contraction active deformations are triggered by the polymerization and depolymerization of the actin filaments and only take place in the solid phase of the active cells (Sect. 2.1). They are expressed as uniaxial cyclic deformations through the solid active strain tensor $\boldsymbol{F}_{a, s a}$ (Sect. A.2) as follows:

$$
\boldsymbol{F}_{a, s a}=e_{a, k} \boldsymbol{i}_{x} \otimes \boldsymbol{i}_{x}
$$

where $e_{a, k}$ will be defined more precisely later on for each type of collective migration adopted by the cell population.

\subsection{Synchronization}

In addition to intra-synchronization, which is a key aspect in single cell migration (Allena and Aubry 2012), in collective cell migration cells need to coordinate their movement (inter-synchronization) in order to be as efficient as possible during the whole process. These two fundamental aspects are described in more details in the next sections.

\subsubsection{Intra-Synchronization}

Single cell migration is usually described as a cyclic process occurring in four (Flaherty et al. 2007) or five (Meili et al. 2010; Sheetz et al. 1999) separate steps: (i) protrusion, (ii) frontal adhesion, (iii) contraction, (iv) rear adhesion, and (v) relaxation. Nevertheless, we have shown in Allena and Aubry (2012) that a minimal rate of adhesion at the rear and at the front of the cell is necessary during the protrusion and the contraction phases, respectively, otherwise the cell would only deform in place or slightly sliding over the surface. According to this remark, similarly to Allena and Aubry (2012), only two phases have been modeled here: (i) simultaneous protrusion of the frontal edge of the cell and adhesion at its rear edge, and (ii) simultaneous contraction of the back of the cell and adhesion at its frontal edge. Thus, we need to synchronize the adhesion forces $\boldsymbol{f}_{\text {adh }}$ introduced in Eq. (1) with the active deformations that have already been defined in Sect. 2.2. Such forces are assumed to be viscous (Allena and Aubry 2012; Friedl and Wolf 2010; Phillipson et al. 2006; Sakamoto et al. 2011) and may be distinguished into a frontal $\left(\boldsymbol{f}_{f}\right)$ and a rear $\left(\boldsymbol{f}_{r}\right)$ force as follows:

$$
\begin{aligned}
& \boldsymbol{f}_{f}(\boldsymbol{n})=-\mu_{f} h_{e}\left(-\frac{\partial e_{a, k}}{\partial t}\right) h_{s f_{i, j}}(\boldsymbol{u}) h_{a, k}(\boldsymbol{p}) \frac{\partial \boldsymbol{u}}{\partial t} \\
& \boldsymbol{f}_{r}(\boldsymbol{n})=-\mu_{r} h_{e}\left(\frac{\partial e_{a, k}}{\partial t}\right) h_{s r_{i, j}}(\boldsymbol{u}) h_{a, k}(\boldsymbol{p}) \frac{\partial \boldsymbol{u}}{\partial t}
\end{aligned}
$$

where $\boldsymbol{n}$ is the normal vector to the boundary of the cell $c(i, j), \mu_{f}$, and $\mu_{r}$ are the friction force viscosities and $\boldsymbol{u}$ is the displacement of the cell $c(i, j)$ with respect to the ECM. The characteristic function $h_{e}$ is the key ingredient of the previous equations since it links the adhesion forces exerted by the cell $c(i, j)$ on the ECM with the pulsating movement of the cell $c(i, j)$. Thus, we have that: (i) when the cell protrudes (i.e. $\left.h_{e}\left(\frac{\partial e_{a, k}}{\partial t}\right)=1\right)$, it simultaneously adheres at the back (i.e. $\left.h_{s r_{i, j}}(\boldsymbol{u})\right)$ while 
(ii) when the cell contracts (i.e. $h_{e}\left(-\frac{\partial e_{a, k}}{\partial t}\right)=1$ ), it simultaneously adheres at the front (i.e. $\left.h_{s f_{i, j}}(\boldsymbol{u})\right)$.

The characteristic function $h_{a, k}(\boldsymbol{p})$ defines which cells inside the cells network $h_{n}(\boldsymbol{p})$ are active. As described later on (Sect. 2.3.2), according to the mode of collective migration adopted by the cell population, all the cells or only few of them may be active. Thus, the active cells network $h_{a, k}(\boldsymbol{p})$ may coincide or not with the cell network $h_{n}(\boldsymbol{p})$. Consequently, the frontal $\left(\boldsymbol{f}_{f}(\boldsymbol{n})\right)$ and the rear $\left(\boldsymbol{f}_{r}(\boldsymbol{n})\right)$ adhesion forces are only applied in those active cells belonging to $h_{a, k}(\boldsymbol{p})$.

\subsubsection{Inter-Synchronization}

As mentioned above (Sect. 1.2), it is still unclear whether all the cells actively move forward or only the leader cells of the population migrate and pull the followers (Weijer 2009). For instance, in the lateral line primordium in Zebrafish as well as in other biological models such as Dictyostelium and Drosophila (Weijer 2009), the cells are believed to follow chemoattractant gradients that guide the collective movement. Furthermore, recent observations using epithelial monolayers have pointed out the presence of a mechanical wave that slowly spans the population and progressively transmits the forces from the leading edge to the centre of the cell sheet (Serra-Picamal et al. 2012). Accordingly, a cell can migrate only if an adjacent cell creates space, which leads to local cell unjamming, or if it pulls on the shared cell-cell junctions.

To evaluate the mechanical interplay between intra- and inter-synchronization, five different modes of collective migration of the cell population have been tested. For each one of them, the intra-synchronization inside the active cells is triggered off by a specific signal, which regulates the active strain $e_{a, k}$ inside the cells and the inter-synchronization between the cells:

(1) strain gradient signal (or chemoattractant migration): the protrusion-contraction deformations inside the active cells are controlled by a gradient with highest intensity at the bow of the ellipse and lowest at the stern;

(2) traveling wave with pulse signal (or worm-like migration): the migration is regulated by a wave which progressively and repeatedly covers the population and temporarily activates one by one the cell rows $r(i)$;

(3) traveling wave with random unit step signal (or tsunami-like migration): a wave gradually spans the cell rows $r(i)$ of the ellipse and randomly activates the cells inside them that permanently acquire the motility phenotype and start migrating with their own pace which is synchronized with the one of the frontal and the rear neighbor cells;

(4) traveling wave with gradient random unit step signal (or chemoattractant tsunami-like migration): this mode of migration is a combination of mode (1) and (3). In fact, the population movement is simultaneously triggered by a strain gradient and a traveling wave with a random unit step signal;

(5) random signal (or random migration): the intensity and the period of the protrusion-contraction deformations inside the active cells randomly vary within the cohort. The cells migrate in a de-synchronized manner.

Each one of these migration modes requires a specific and complex inter-synchronization, which will be described in the following sections. 
Strain Gradient Signal (or Chemoattractant Migration) In this mode of collective movement, all the cells inside the cohort are active so that $h_{a, 1}(\boldsymbol{p})=h_{n}(\boldsymbol{p})$ (Eq. (9)) and $h_{q, 1}(\boldsymbol{p})=0$. Furthermore, the active cells migrate with the same intrasynchronization (i.e. they all protrude or contract simultaneously). The active deformations (protrusion and contraction) are regulated by a strain gradient. Thus, the leading cells sense more the signal than the cells in the back of the population and undergo larger strains during both the protrusion and the contraction phases. Consequently, the active deformation $e_{a, 1}(\boldsymbol{p})$ is defined as follows:

$$
e_{a, 1}(\boldsymbol{p})=e_{a 0} \frac{\left(\boldsymbol{p}-\boldsymbol{p}_{\text {stern }}, \boldsymbol{p}_{\text {bow }}-\boldsymbol{p}_{\text {stern }}\right)}{L} \sin \left(2 \pi \frac{t}{T}\right) h_{a, 1}(\boldsymbol{p})
$$

where $e_{a 0}$ is the amplitude of the active strain, $\boldsymbol{p}_{\text {stern }}$ and $\boldsymbol{p}_{\text {bow }}$ are the initial position of the stern and the bow of the ellipse, respectively, and $T$ is the duration of a migration cycle.

Traveling Wave with Pulse Signal (or Worm-Like Migration) This mode of collective migration is very similar to the one used by worms in which locomotion is triggered by waves of contraction and relaxation of alternate muscles. Here, the wave progressively and repeatedly (traveling wave) spans the cell population and temporarily (pulse signal) activates one by one the cell rows $r(i)$ (Eq. (12)), which are promptly deactivated as soon as the wave has passed by. Therefore, only one row is active at the time and the active deformation $e_{a, 2}(\boldsymbol{p}, t)$ is expressed as

$$
e_{a, 2}(\boldsymbol{p}, t)=e_{a 0} \sin \left(2 \pi \frac{t}{T}\right) h_{a, 2}(\boldsymbol{p}, t)
$$

with $h_{a, 2}(\boldsymbol{p}, t)$ defined in Eq. (20).

Traveling Wave with Random Unit Step Signal (or Tsunami-Like Migration) In the third mode of collective migration, a wave gradually (traveling wave) covers the cell population like a tsunami and permanently (unit step signal) 'turns on' one by one the rows of cells that acquire the motile phenotype and start migrating at their own pace. Three fundamental aspects have to be considered.

First, contrarily to the previous case (Sect. Traveling Wave with Pulse Signal (or Worm-Like Migration)), more than one row is active at the time now and the wave spans only once the ellipse.

Second, not all the cells inside the activated rows may acquire the motile phenotype (random unit step signal). However, some of them may remain quiescent, which leads to a random distribution of the active cells inside the population. The number of active cells in a row may vary from 1 to $n_{c}$, which is the total number of cells in a row. Such a configuration is determined by a parameter $\tau_{i, j}$, proper to each cell $c(i, j)$, which can be equal to 0 (quiescent cell) or 1 (active cell) and changes every 6 hours (Fig. 3).

Third, according to the experimental observations (Serra-Picamal et al. 2012), a cell can only move if the adjacent cell creates space or pulls on the shared cell-cell junctions. Thus, a perfect inter-synchronization between the cell $c(i, j)$ and its two 


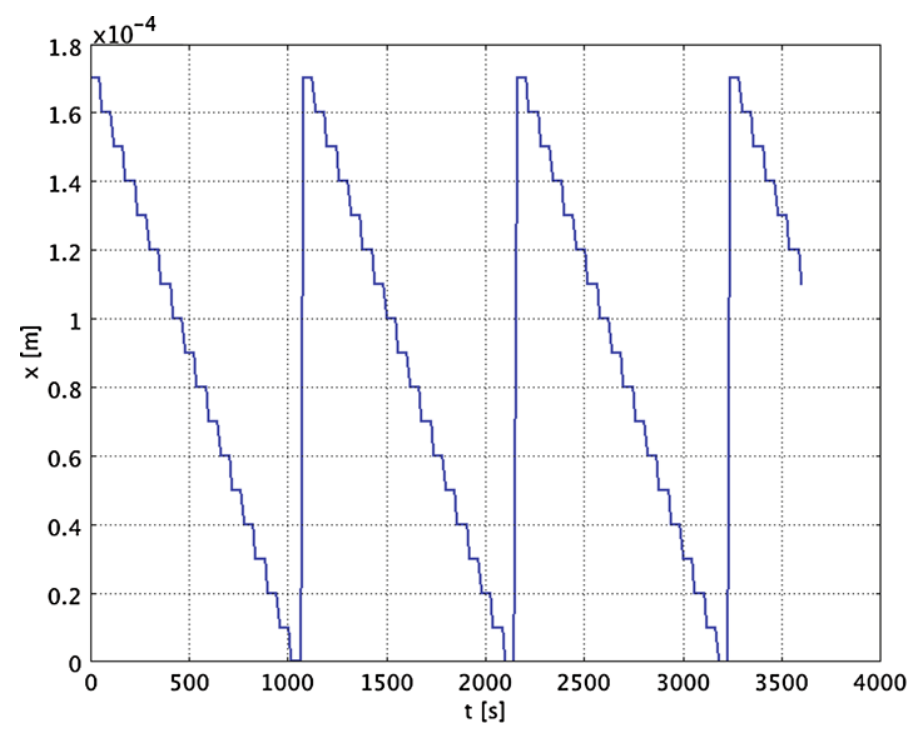

Fig. 2 Trend of the traveling wave, which defines the spatial coordinate $c_{i, j_{x}}(t)$ of the temporary active row for the worm-like migration (only $1 \mathrm{~h}$ is represented)

Fig. 3 Random distribution of the active cells network

$h_{a, 3}(\boldsymbol{p}, t)$ between $0-6 \mathrm{~h}(\mathbf{a})$, $6 \mathrm{~h}-12 \mathrm{~h}(\mathbf{b}), 12 \mathrm{~h}-18 \mathrm{~h}$ (c) and $18 \mathrm{~h}-24 \mathrm{~h}$ (d) for the

tsunami-like migration. In red the active cells $\left(\tau_{i, j}=1\right)$ and in blue the quiescent cells $\left(\tau_{i, j}=0\right)$ (Color figure online)
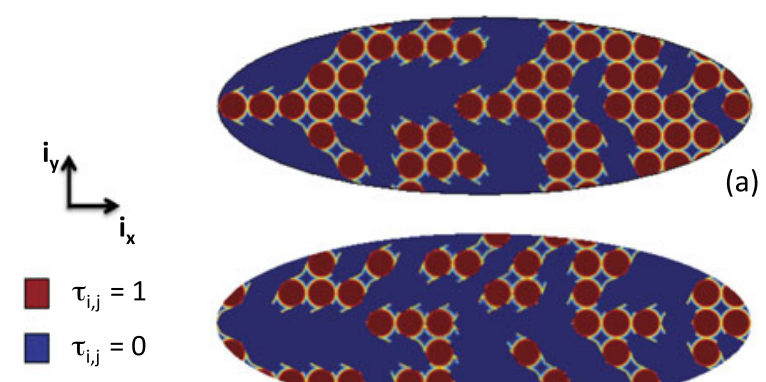

(a)
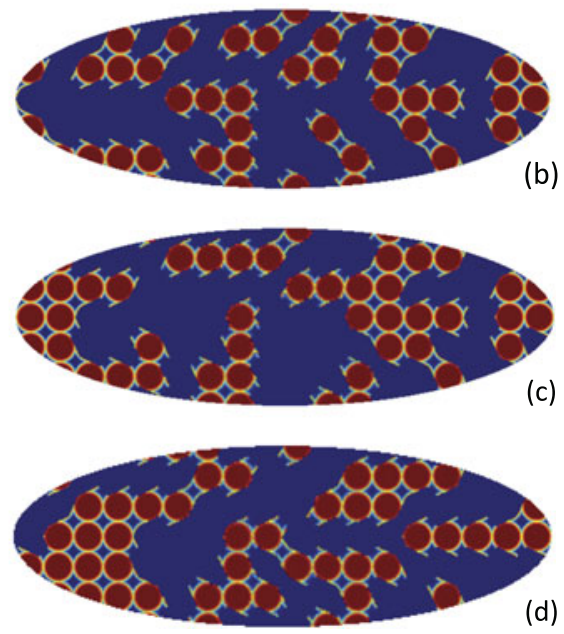

adjacent cells on the same transversal coordinate $j$ in the front $(c(i+1, j))$ and in the back $(c(i-1, j))$ is required. Specifically, the intra-synchronization inside the cell $c(i, j)$ must be out of phase with respect to the intra-synchronization of the 
cells $c(i+1, j)$ and $c(i-1, j)$. Thus, when the cell $c(i+1, j)$ protrudes, the cell $c(i, j)$ contracts and the cell $c(i-1, j)$ protrudes; when the cell $c(i+1, j)$ contracts, the cell $c(i, j)$ protrudes and the cell $c(i-1, j)$ contracts. Furthermore, the inter-synchronization has to be coordinated with the wave that covers the ellipse and activates the cell rows (Eq. (23)). Therefore, a particular form of the active deformation $e_{a, 3}(\boldsymbol{p}, t)$ is implemented as follows:

$$
e_{a, 3}(\boldsymbol{p}, t)=e_{a 0} \sin \left(2 \pi \frac{t-\frac{T}{2}\left(i_{\max }-i\right)}{T}\right) h_{a, 3}(\boldsymbol{p}, t)
$$

with $h_{a, 3}(\boldsymbol{p}, t)$ the characteristic function describing the active cells network and defined in Eq. (22).

According to Eq. (6), the first cells to be 'turned on' and to deform are the ones inside the leading row of the ellipse $\left(i=i_{\max }\right)$, while the other cells are gradually stimulated by the wave. After a period of $\frac{T}{2}\left(i_{\max }-i\right)$ the wave has spanned the entire length of the ellipse, thus each active cell is able to migrate at its proper pace.

Traveling Wave with Gradient Unit Step Signal (or Chemoattractant Tsunami-Like Migration) The fourth mode of collective migration combines the strain gradient migration and the traveling wave migration. The active cells are randomly distributed inside the cohort as in the third mode of migration (Sect. Traveling Wave with Random Unit Step Signal (or Tsunami-Like Migration)), so that $h_{a, 4}(\boldsymbol{p})=h_{a, 3}(\boldsymbol{p})$ (Eq. (22)), and change their configuration every 6 hours (Fig. 3). A wave progressively covers the ellipse and permanently 'turns on' the active cells. Therefore, the intra-synchronization proper to each cell $c(i, j)$ is out of phase with respect to the intra-synchronization of the cell $c(i+1, j)$ and the cell $c(i-1, j)$ on the same transversal coordinate $j$, as described in Sect. Traveling Wave with Random Unit Step Signal (or Tsunami-Like Migration). Furthermore, the active deformations (protrusion and contraction) are regulated by a gradient as in the first mode of migration (Sect. Strain Gradient Signal (or Chemoattractant Migration)). Accordingly, $e_{a, 4}(\boldsymbol{p}, t)$ reads

$$
e_{a, 4}(\boldsymbol{p}, t)=e_{a 0} \frac{\left(\boldsymbol{p}-\boldsymbol{p}_{\text {stern }}, \boldsymbol{p}_{\text {bow }}-\boldsymbol{p}_{\text {stern }}\right)}{L} \sin \left(2 \pi \frac{t-\frac{T}{2}\left(i_{\text {max }}-i\right)}{T}\right) h_{a, 4}(\boldsymbol{p})
$$

Random Signal In this mode of collective migration, all the cells inside the population are active $\left(h_{a, 5}(\boldsymbol{p})=h_{n}(\boldsymbol{p})\right.$, Eq. (9) and $\left.h_{q, 5}(\boldsymbol{p})=0\right)$. Nevertheless, contrarily to the first mode of migration (Sect. Strain Gradient Signal (or Chemoattractant Migration)), the cells migrate out of phase since each one of them has its own migration period $T_{i j}$, which ranges between $40 \mathrm{~s}$ and $180 \mathrm{~s}$ (Fig. 4b), and amplitude of the active strain $e_{a 0_{i j}}$, which may be comprised between 0.1 and 0.6 (Fig. 4a). Thus, $e_{a, 5}(\boldsymbol{p}, t)$ is expressed as

$$
e_{a, 5}(\boldsymbol{p}, t)=e_{a 0_{i j}} \sin \left(2 \pi \frac{t}{T_{i j}}\right) h_{a, 5}(\boldsymbol{p})
$$


Fig. 4 Random values of the cyclic component $e_{a 0, i j}$ of the active strain $e_{a 0}$ (a) and of the migration period $T_{i j}$ (b) for the random migration
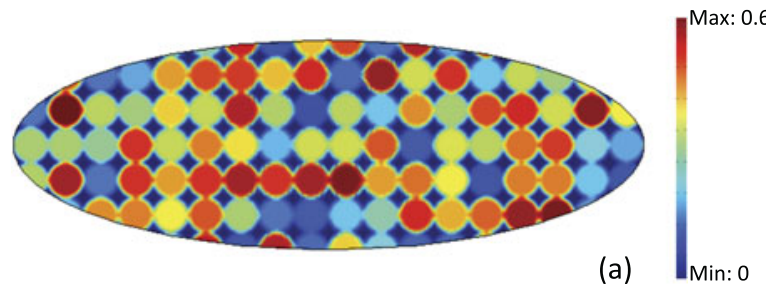

(a)

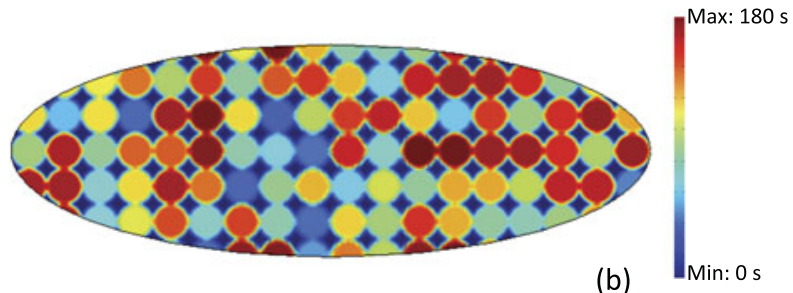

\section{Results}

The simulations were run using the finite element software COMSOL Multiphysics ${ }^{\circledR}$ $3.5 \mathrm{a}$ and reproduced an interval time of 1 day. The cell population has an initial geometry with semi-axes $L$ and $l$ equal to $90 \mu \mathrm{m}$ and $30 \mu \mathrm{m}$, respectively (Fig. 1a). The cell network represented by $h_{n}(\boldsymbol{p})$ includes 18 cell rows $\left(N_{c}=i_{\max }=18\right.$, Appendix A.1) and each cell $c(i, j)$ has a radius $r_{c}=5 \mu \mathrm{m}$ (Allena 2013; Allena and Aubry 2012). The distances $l_{f}$ and $l_{r}$ have been fixed to $2 \mu \mathrm{m}$ (Allena 2013; Allena and Aubry 2012), which leads to an area of $25 \mu \mathrm{m}^{2}$ covered by the adhesion surfaces $\partial \Omega_{s f_{i, j}}$ and $\partial \Omega_{s r_{i, j}}$ (Fig. 1d) and the friction force viscosities $\mu_{f}$ and $\mu_{r}$ have been set to $10^{8} \mathrm{~Pa} / \mathrm{m}$ (Allena 2013; Allena and Aubry 2012). For the active cells (Sect. 2.2), the Young moduli of the solid elastic $\left(E_{a, s e}\right)$ and the fluid elastic $\left(E_{a, f e}\right)$ phases have been chosen equal to $10^{4} \mathrm{~Pa}$ (Allena 2013; Allena and Aubry 2012; Laurent et al. 2005) and $100 \mathrm{~Pa}$ (Allena 2013; Allena and Aubry 2012), respectively. The Poisson ratios $v_{a, s e}$ and $v_{a, f e}$ have been set to 0.3 and 0.4 , while the viscosity $\mu_{a, f v}$ of the fluid viscous phase has been set to $3 \times 10^{5} \mathrm{~Pa} \mathrm{~s}$ (Bausch et al. 1999; Drury and Dembo 2001). For the quiescent cells (Sect. 2.2), the Young moduli $E_{q, s e}$ and $E_{q, f e}$ of the solid elastic and fluid elastic phases are equal to $400 \mathrm{~Pa}$ (Soofi et al. 2009) and $100 \mathrm{~Pa}$ (Allena 2013; Allena and Aubry 2012), respectively. The Poisson ratios $v_{q, s e}$ and $v_{q, f e}$ are equal to 0.3 and 0.4 , respectively, while the viscosity $\mu_{q, f v}$ of the fluid viscous phase has been set to $3 \times 10^{5} \mathrm{Pas}$ (Bausch et al. 1999; Drury and Dembo 2001). It has to be remembered that for the worm-like (Sect. Traveling Wave with Pulse Signal (or Worm-Like Migration)), the tsunami-like (Sect. Traveling Wave with Random Unit Step Signal (or Tsunami-Like Migration)) and the chemoattractant tsunami-like (Sect. Traveling Wave with Gradient Unit Step Signal (or Chemoattractant Tsunami-Like Migration)) modes of migration, the cells may switch from an active to a quiescent state or vice versa. Therefore, in these cases the Young modulus of the cells is described as a function of their state with respect to time.

Furthermore, the Young modulus $E_{\mathrm{ECM}}$ and the viscosity $\mu_{\mathrm{ECM}}$ of the ECM have been fixed to $10 \mathrm{~Pa}$ and $3 \times 10^{5} \mathrm{~Pa}$ s (Bausch et al. 1999; Drury and Dembo 2001), 
respectively, and the density of the cells is equal to $1000 \mathrm{~kg} / \mathrm{m}^{3}$ (Fukui et al. 2000). Finally, the intensity of the cyclic active strain $e_{a 0}$ and the duration of a migration cycle $T$ have been set to 0.5 (Allena 2013; Allena and Aubry 2012) and $60 \mathrm{~s}$ (Allena 2013; Allena and Aubry 2012; Dong et al. 2002) respectively (except for the fifth mode of migration as described in Sect. Random Signal). $e_{a 0}$ is the same during both the protrusion and the contraction phase, although in single cell migration the contraction strain is usually smaller than the protrusion deformation (Giannone et al. 2007). The main geometrical, mechanical, and material parameters of the model are listed in Table 1.

\subsection{Efficiency}

As pointed out in Allena and Aubry (2012), the intra-synchronization (i.e. the synchronization between active strains and the adhesion forces) is a key factor in single cell migration. Nevertheless, it is not a sufficient condition in collective cell migration during which inter-synchronization (i.e. synchronization between the cells) is even more important. In fact, a tight synergy between the active deformations (protrusion and contraction) and the adhesion forces in each cell does not guarantee an efficient movement of the population (i.e. the cells may move in wrong directions and out of phase with respect to their neighbours). The cells need to communicate and adapt themselves in order to coordinate their movement and properly move forward together. In order to evaluate the interdependence between the intra- and the intersynchronization, we have tested five different types of collective migration, which may reproduce realistic or unrealistic behaviors. In this section, we will analyse the efficiency (i.e. covered distance over 1 day) and discuss the reliability of each mode of migration.

In the first type of collective migration, the cell active strains are regulated by a gradient (Eq. (4)), so that the cells at the bow of the ellipse undergo larger deformations than the cells at the stern of the ellipse. Since all the cells are active and have the same intra-synchronization, they all protrude and contract simultaneously, but such a configuration induces a wrong movement of the population (Movie 1) (ESM). During protrusion, the leading cells freely and correctly deform, while the follower cells show two different behaviors. In the central region of the cohort, they are completely inhibited since their elongating leading edge hits the adhering rear edge of the cells in front of them. In the back of the cohort instead, they incorrectly deform because, due to the constriction imposed by the rear edge of the frontal neighbours, the deformation interferes with the back of the cell, which is free and, therefore, the cell elongates in the opposite direction. During contraction, the follower cells correctly move forward. However, the leading cells unsuccessfully pull their back, which is linked through the cell-cell junctions to the adhering frontal edge of the cells behind them. Thus, a contraction of the frontal edge of these cells occurs. Such a microscopic behavior leads to a global movement of the cell population very similar to the one of an accordion, which is overall poorly efficient. The cell population in fact only covers a distance of about $520 \mu \mathrm{m}$ after 1 day (Fig. 5, blue ellipse), with a steady state speed of about $0.006 \mu \mathrm{m} / \mathrm{s}$.

The second type of collective migration reproduces the locomotion mode of worms in which alternate muscles elongate and contract. To describe such behavior, 
Table 1 Geometrical, mechanical and material parameters of the model

\begin{tabular}{|c|c|c|c|c|}
\hline Parameter & Description & Value & Unit & Reference \\
\hline$L$ & Major axis of the ellipse & 90 & $\mu \mathrm{m}$ & \\
\hline$l$ & Minor axis of the ellipse & 30 & $\mu \mathrm{m}$ & \\
\hline$N_{c}$ & $\begin{array}{l}\text { Number of cells along the axis } L \text { of the } \\
\text { ellipse }\end{array}$ & 18 & & \\
\hline$n_{c, \max }$ & $\begin{array}{l}\text { Maximal number of cells along the axis } \\
l \text { of the ellipse }\end{array}$ & 6 & & \\
\hline$r_{c}$ & Cell radius & 5 & $\mu \mathrm{m}$ & $\begin{array}{l}\text { (Allena 2013; Allena and } \\
\text { Aubry 2012) }\end{array}$ \\
\hline$l_{f}$ & $\begin{array}{l}\text { Distance of the boundary of the frontal } \\
\text { adhesion surface from the cell centre }\end{array}$ & 2 & $\mu \mathrm{m}$ & $\begin{array}{l}\text { (Allena 2013; Allena and } \\
\text { Aubry 2012) }\end{array}$ \\
\hline$l_{r}$ & $\begin{array}{l}\text { Distance of the boundary of the rear } \\
\text { adhesion surface from the cell centre }\end{array}$ & 2 & $\mu \mathrm{m}$ & $\begin{array}{l}\text { (Allena 2013; Allena and } \\
\text { Aubry 2012) }\end{array}$ \\
\hline$\partial \Omega_{s f_{i, j}}$ & Area of frontal adhesion region & 25 & $\mu \mathrm{m}^{2}$ & \\
\hline$\partial \Omega_{s r_{i, j}}$ & Area of rear adhesion region & 25 & $\mu \mathrm{m}^{2}$ & \\
\hline$\mu_{f}$ & $\begin{array}{l}\text { Friction force viscosity of the frontal } \\
\text { adhesion surface } \partial \Omega_{s f_{i, j}}\end{array}$ & $10^{8}$ & $\mathrm{Pas} / \mathrm{m}$ & $\begin{array}{l}\text { (Allena 2013; Allena and } \\
\text { Aubry 2012) }\end{array}$ \\
\hline$\mu_{r}$ & $\begin{array}{l}\text { Friction force viscosity of the rear } \\
\text { adhesion surface } \partial \Omega_{s r_{i, j}}\end{array}$ & $10^{8}$ & $\mathrm{Pas} / \mathrm{m}$ & $\begin{array}{l}\text { (Allena 2013; Allena and } \\
\text { Aubry 2012) }\end{array}$ \\
\hline$\rho$ & Cells density & 1000 & $\mathrm{~kg} / \mathrm{m}^{3}$ & (Fukui et al. 2000) \\
\hline$E_{a, s e}$ & $\begin{array}{l}\text { Young modulus of the solid elastic } \\
\text { phase of the active cells }\end{array}$ & $10^{4}$ & $\mathrm{~Pa}$ & $\begin{array}{l}\text { (Allena 2013; Allena and } \\
\text { Aubry 2012; Ilina and } \\
\text { Friedl 2009) }\end{array}$ \\
\hline$v_{a, s e}$ & $\begin{array}{l}\text { Poisson ratio of the solid elastic phase } \\
\text { of the active cells }\end{array}$ & 0.3 & & \\
\hline$E_{a, f e}$ & $\begin{array}{l}\text { Young modulus of the fluid elastic } \\
\text { phase of the active cells }\end{array}$ & 100 & $\mathrm{~Pa}$ & $\begin{array}{l}\text { (Allena 2013; Allena and } \\
\text { Aubry 2012) }\end{array}$ \\
\hline$v_{a, f e}$ & $\begin{array}{l}\text { Poisson ratio of the fluid elastic phase } \\
\text { of the active cells }\end{array}$ & 0.4 & & \\
\hline$\mu_{a, f v}$ & $\begin{array}{l}\text { Viscosity of the fluid viscous phase } \\
\text { of the active cells }\end{array}$ & $3 \times 10^{5}$ & $\mathrm{Pas}$ & $\begin{array}{l}\text { (Bausch et al. 1999; Drury } \\
\text { and Dembo 2001) }\end{array}$ \\
\hline$E_{q, s e}$ & $\begin{array}{l}\text { Young modulus of the solid elastic } \\
\text { phase of the quiescent cells }\end{array}$ & 400 & $\mathrm{~Pa}$ & $\begin{array}{l}\text { (Sherratt and Murray } \\
\text { 1991) }\end{array}$ \\
\hline$v_{q, s e}$ & $\begin{array}{l}\text { Poisson ratio of the solid elastic phase } \\
\text { of the active cells }\end{array}$ & 0.3 & & \\
\hline$E_{q, f e}$ & $\begin{array}{l}\text { Young modulus of the fluid elastic } \\
\text { phase of the active cells }\end{array}$ & 100 & $\mathrm{~Pa}$ & $\begin{array}{l}\text { (Allena 2013; Allena and } \\
\text { Aubry 2012) }\end{array}$ \\
\hline$v_{q, f e}$ & $\begin{array}{l}\text { Poisson ratio of the fluid elastic phase } \\
\text { of the active cells }\end{array}$ & 0.4 & & \\
\hline$\mu_{q, f v}$ & $\begin{array}{l}\text { Viscosity of the fluid viscous phase of } \\
\text { the active cells }\end{array}$ & $3 \times 10^{5}$ & Pas & $\begin{array}{l}\text { (Bausch et al. 1999; Drury } \\
\text { and Dembo 2001) }\end{array}$ \\
\hline$E_{\mathrm{ECM}}$ & Young modulus of the ECM & 10 & $\mathrm{~Pa}$ & \\
\hline$\mu_{\mathrm{ECM}}$ & Viscosity of the ECM & $3 \times 10^{5}$ & Pas & $\begin{array}{l}\text { (Bausch et al. 1999; Drury } \\
\text { and Dembo 2001) }\end{array}$ \\
\hline
\end{tabular}


Table 1 (Continued)

\begin{tabular}{|c|c|c|c|c|}
\hline Parameter & Description & Value & Unit & Reference \\
\hline$e_{a 0}$ & $\begin{array}{l}\text { Intensity of the cyclic active strain } \\
\text { (for modes of migration } 1,2,3 \text { and } 4 \text { ) }\end{array}$ & 0.5 & & $\begin{array}{l}\text { (Allena 2013; Allena and } \\
\text { Aubry 2012) }\end{array}$ \\
\hline$T$ & Duration of a migration cycle & 60 & s & $\begin{array}{l}\text { (Allena 2013; Allena and } \\
\text { Aubry 2012; Dong et al. } \\
\text { 2002) }\end{array}$ \\
\hline
\end{tabular}

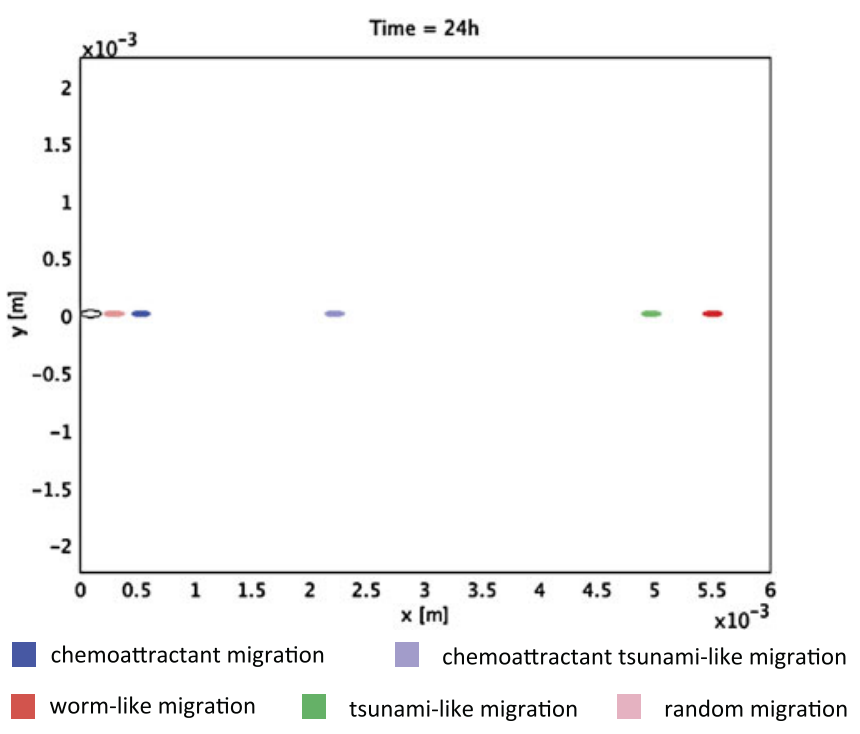

Fig. 5 The distance covered by the cell population after $24 \mathrm{~h}$ for the different modes of migration: chemoattractant migration (blue), worm-like migration (red), tsunami-like migration (green), chemoattractant tsunami-like migration (purple), random migration (pink) (Color figure online)

a traveling wave has been used to temporarily activate one by one the cell rows inside the ellipse. Each row remains active for one migration cycle $T$ and it is promptly deactivated has soon as the wave has passed by. The cells inside the active row have the same intra-synchronization, thus they protrude and contract simultaneously (Movie 2) (ESM). Their movement correctly takes place since the cells in front and behind them during protrusion and contraction respectively, are momentarily quiescent and, therefore, easily deformable (see Sect. Traveling Wave with Pulse Signal (or Worm-Like Migration)). Nevertheless, the leading and the following cells appear to be more efficient than the cells in the central region of the ellipse. In this case, the cell population covers a total distance of $5430 \mu \mathrm{m}$ during 1 day (Fig. 5, red ellipse), with a steady state speed of $0.06 \mu \mathrm{m} / \mathrm{s}$.

The third mode of collective migration is based on a complex inter-synchronization according to which a perfect coordination between the cell $c(i, j)$ and its frontal $(c(i+1, j))$ and rear $(c(i-1, j))$ neighbor cells is required. As experimentally observed (Serra-Picamal et al. 2012), a traveling wave progressively covers the cells 
population and permanently 'turns on' one by one the cell rows in the ellipse. However, not all the cells in each row may be activated, thus a random distribution of the active cells is obtained. In our model, such an aspect has been taken into account by introducing a specific parameter, which allows defining the active $\left(\tau_{i, j}=1\right)$ or the quiescent $\left(\tau_{i, j}=0\right)$ cells in each row. The random configuration changes every 6 hours (Fig. 3). In Movie 3 (ESM), it is possible to observe the successive phases of the collective migration over a period of 1 hour. The inter-synchronization allows the cell $c(i, j)$ to move out of phase with respect to its frontal $c(i+1, j)$ and rear $c(i-1, j)$ neighbours. Thus, the active cells in the leading row $(r(18)$, Fig. 1c) are the first to be activated and to elongate. As soon as their contraction phase starts $(t=30 \mathrm{~s})$, the active cells in the follower row ( $r(17)$, Fig. 1c) elongate and so on. In this way, the accordion movement observed in the first mode of migration does not occur anymore, but all the cells belonging to the active cells network (Sect. Traveling Wave with Random Unit Step Signal (or Tsunami-Like Migration)) actively participate to the movement with their proper intra-synchronization. After 1 day, the cohort has covered a distance of $4340 \mu \mathrm{m}$ (Fig. 5, green ellipse) at a steady state speed of $0.05 \mu \mathrm{m} / \mathrm{s}$.

As mentioned above, the cyclic component $e_{a 0}$ of the active deformation is the same during both the protrusion and the contraction phase. Nevertheless, a smaller contraction with respect to the protrusion could have been considered, as it is the case in single cell migration (Giannone et al. 2007). In this case, the cell $c(i, j)$ would elongate with the same intensity of the contraction of the cell $c(i+1, j)$, the cell $c(i-1, j)$ would elongate with the same intensity of the contraction of the cell $c(i, j)$ and so on. Thus, the cells would adapt themselves and we would observe a 'natural' gradient of the active deformation.

The fourth type of migration combines the modes of movement described for the first and the third types of migration. Thus, a coupling between the chemoattractant gradient (Sect. Strain Gradient Signal (or Chemoattractant Migration)) and the traveling wave (Sect. Traveling Wave with Random Unit Step Signal (or Tsunami-Like Migration)) is implemented (Movie 4) (ESM). In this case, the population covers a distance of $2850 \mu \mathrm{m}$ in 1 day (Fig. 5, purple ellipse; steady state speed of $0.03 \mu \mathrm{m} / \mathrm{s}$ ).

Considering the covered distance, the modes of migration explored so far are very efficient, with the worm-like and the chemoattractant migration being the most and the least powerful respectively (Fig. 5). Nevertheless, one may wonder if such types of collective migration can be in some way related to the experimental observations. In fact, despite their efficiency, each one of the modes of migration presents 'observed' and 'not observed' features:

- in the chemoattractant migration all the cells are active (observed), but they migrate perfectly in phase (not observed);

- in the worm-like migration a wave successively activates and deactivates the rows of cells (not observed), but then only one row at the time is active (not observed) within which the cells show a behavior similar to the one of single cell migration (observed);

- in the tsunami-like migration, a wave spans the entire population and permanently activates the cells (observed) which then perfectly migrate out of phase (not observed); 
- in the chemoattractant tsunami-like migration, a wave progressively activates the cells (observed) which then acquire a motility phenotype and start to migrate perfectly out of phase (not observed), but with different intensities as they felt a chemical gradient from the bow to the stern of the ellipse (observed).

Therefore, as a common feature, each mode of migration shows a perfect intersynchronization within the population, which is regulated using specific analytical approaches. Although such a synchronization seems to be very simple to achieve from a theoretical point of view, it is much more complex to acquire in reality. In fact, cells within a population naturally tend to de-synchronize with respect to their neighbours, which leads to a random behavior of the cells inside the cohort. Given these remarks, a fifth mode of migration has been tested in which all the cells are active and the protrusion-contraction deformations are regulated by specific values of the intensity $e_{a 0_{i j}}$ and the period $T_{a_{i j}}$ that randomly vary within the cell cohort (Figs. 4a and b). In Movie 5 (ESM) it is possible to observe the successive phases of the collective migration over $1 \mathrm{~h}$. Each cell migrates at its own pace, which results in a not necessarily coordinated movement with the neighbor cells. Thus, the overall efficiency of the population is compromised since the de-synchronization between the cells may inhibit their correct protrusion-contraction movement. Actually, the cell population only covers a distance of about $210 \mu \mathrm{m}$ (Fig. 5, pink ellipse; steady state speed of $0.002 \mu \mathrm{m} / \mathrm{s}$ ), which is then the smallest covered distance compared to the previous cases. Despite this apparent limitation, the random behavior represents a realistic feature of the model. Nevertheless, it is evident that, for the population to be efficient, randomness has to be coupled with a certain minimal level of inter-synchronization. This actually corresponds to what has been observed by SerraPicamal et al. (2012) according to which a mechanical wave spans the layer of cells that successively start to migrate. In practice, the cells adjust their movement according to the local stress state that is gradually developed by the migration of the nearby cells. From a theoretical point of view, this can be described by linking the active deformation $e_{a}$ of each cell to the stress state of its neighbor cells. Thus, the first cells to migrate would be the ones at the leading and free edge of the ellipse and then the followers would naturally be activated because stimulated by the stresses generated around them. Therefore, a mechanotactic signal would be transmitted within the population. We are currently considering such an aspect in order to improve the present model.

\subsection{Principal Stresses}

Looking at principal stresses magnitudes and directions is a useful way to understand how the mechanical forces are transmitted inside and between the cells. In Table 2, we have reported the values of the average principal stresses during both protrusion and contraction for each mode of migration. Additionally, we have calculated them over the whole active cells network $\Omega_{a, k}$ and inside a leading $(c(18,4)$ in Fig. 1c), a central $(c(10,4)$ in Fig. 1c), and a rear $(c(1,4)$ in Fig. 1c) cell. As expected, we observe a compression during the protrusion and a traction during the contraction. Although the stress regime may vary according to the mode of migration adopted by the cohort, few general remarks may be pointed out. 
Table 2 Average principal stress calculated within the active cells network and inside a leading $(c(18,4))$, a central $(c(10,4))$, and a rear $(c(1,4))$ cell during both protrusion and contraction for each mode of migration

\begin{tabular}{|c|c|c|c|c|c|c|c|c|c|c|}
\hline \multirow{2}{*}{$\begin{array}{l}\text { Average } \\
\text { principal } \\
\text { stress }\end{array}$} & \multicolumn{4}{|c|}{ Active domain } & \multicolumn{2}{|c|}{$\begin{array}{l}\text { Leading cell } \\
c(18,4)\end{array}$} & \multicolumn{2}{|c|}{$\begin{array}{l}\text { Central cell } \\
c(10,4)\end{array}$} & \multicolumn{2}{|c|}{$\begin{array}{l}\text { Follower cell } \\
c(1,4)\end{array}$} \\
\hline & \multicolumn{2}{|c|}{ Protrusion } & \multicolumn{2}{|c|}{ Contraction } & $\begin{array}{l}\text { Protru- } \\
\text { sion }\end{array}$ & $\begin{array}{l}\text { Contrac- } \\
\text { tion }\end{array}$ & $\begin{array}{l}\text { Protru- } \\
\text { sion }\end{array}$ & $\begin{array}{l}\text { Contrac- } \\
\text { tion }\end{array}$ & $\begin{array}{l}\text { Protru- } \\
\text { sion }\end{array}$ & $\begin{array}{l}\text { Contrac- } \\
\text { tion }\end{array}$ \\
\hline Mode 1 & \multicolumn{2}{|c|}{$-1700 \mathrm{~Pa}$} & \multicolumn{2}{|c|}{$2000 \mathrm{~Pa}$} & $-1100 \mathrm{~Pa}$ & $3300 \mathrm{~Pa}$ & $-1600 \mathrm{P}$ & $2000 \mathrm{~Pa}$ & $-30 \mathrm{~Pa}$ & $40 \mathrm{~Pa}$ \\
\hline Mode 2 & \multicolumn{2}{|c|}{$-230 \mathrm{~Pa}$} & \multicolumn{2}{|c|}{$-230 \mathrm{~Pa}$} & $-200 \mathrm{~Pa}$ & $200 \mathrm{~Pa}$ & $-600 \mathrm{~Pa}$ & $600 \mathrm{~Pa}$ & $-200 \mathrm{~Pa}$ & $200 \mathrm{~Pa}$ \\
\hline \multirow[t]{2}{*}{ Mode 3} & $\begin{array}{l}\text { Even } \\
\text { rows }\end{array}$ & $\begin{array}{l}\text { Odd } \\
\text { rows }\end{array}$ & $\begin{array}{l}\text { Even } \\
\text { rows }\end{array}$ & $\begin{array}{l}\text { Odd } \\
\text { rows }\end{array}$ & \multirow[t]{2}{*}{$-200 \mathrm{~Pa}$} & \multirow[t]{2}{*}{$200 \mathrm{~Pa}$} & \multirow[t]{2}{*}{$-500 \mathrm{~Pa}$} & \multirow[t]{2}{*}{$500 \mathrm{~Pa}$} & \multirow[t]{2}{*}{$-200 \mathrm{~Pa}$} & \multirow[t]{2}{*}{$200 \mathrm{~Pa}$} \\
\hline & \multicolumn{4}{|c|}{$\overline{-650 \mathrm{~Pa}-700 \mathrm{~Pa} 650 \mathrm{~Pa} 700 \mathrm{~Pa}}$} & & & & & & \\
\hline \multirow[t]{2}{*}{ Mode 4} & $\begin{array}{l}\text { Even } \\
\text { rows }\end{array}$ & $\begin{array}{l}\text { Odd } \\
\text { rows }\end{array}$ & $\begin{array}{l}\text { Even } \\
\text { rows }\end{array}$ & $\begin{array}{l}\text { Odd } \\
\text { rows }\end{array}$ & \multirow[t]{2}{*}{$-180 \mathrm{~Pa}$} & \multirow[t]{2}{*}{$190 \mathrm{~Pa}$} & \multirow[t]{2}{*}{$-720 \mathrm{~Pa}$} & \multirow[t]{2}{*}{$700 \mathrm{~Pa}$} & \multirow[t]{2}{*}{$-16 \mathrm{~Pa}$} & \multirow[t]{2}{*}{$16 \mathrm{~Pa}$} \\
\hline & \multicolumn{4}{|c|}{$\overline{-380 \mathrm{~Pa}-400 \mathrm{~Pa} 380 \mathrm{~Pa} 400 \mathrm{~Pa}}$} & & & & & & \\
\hline Mode 5 & \multicolumn{2}{|c|}{$-1200 \mathrm{~Pa}$} & \multicolumn{2}{|c|}{$1500 \mathrm{~Pa}$} & \multicolumn{2}{|c|}{$-1050 \mathrm{~Pa} 890 \mathrm{~Pa}$} & \multicolumn{2}{|c|}{$-3250 \mathrm{~Pa} 3210 \mathrm{~Pa}$} & \multicolumn{2}{|c|}{$-2900 \mathrm{~Pa} 3130 \mathrm{~Pa}$} \\
\hline
\end{tabular}

First, the first and the fifth modes of migration are the ones showing the highest concentration of stress within the active domain $\Omega_{a, k}$. Such values are too high compared to the experimental data (Serra-Picamal et al. 2012; Tambe et al. 2011; Trepat et al. 2009), which confirms the inefficiency of these migration modes (Sect. 3.1). However, values are consistent with the experimental observations (Serra-Picamal et al. 2012; Tambe et al. 2011; Trepat et al. 2009) for the second, the third and the fourth modes of migration, which are also the most efficient modes of collective movement (Sect. 3.1).

Second, in the first, second, and fifth modes of migration the principal stresses are mostly orientated along the direction of migration since all the cells inside the cohort or inside the temporarily active row migrate in phase. This is not the case in the third and fourth modes of migration, for which the active cells are randomly distributed within the cohort, and thus the mechanical stresses are transmitted within the population following such configuration (Fig. 3). Nevertheless, in the third mode of migration, few stress concentrations may be noticed at the frontal or at the rear adhesion surfaces in contact with neighbor cells.

Third, the leading $(c(18,4))$ and the rear $(c(1,4))$ cells show a behavior very similar to the one observed in 2D single cell migration during which the cell is only constrained by the contact with the underneath substrate, and it is free at the front and at the back. Actually, the leading cells can freely elongate during the protrusion phase since they do not have any frontal neighbor cell, while the follower cells can freely contract because they do not have to pull any further cells behind them.

As a consequence of the previous remarks, the cells inside the population $(c(10,4))$ generate larger stresses during both protrusion and contraction compared to the leading and the follower cells. This is mostly due to the fact that, with respect to the 'bow' and the 'stern' cells, the central cells have frontal and rear neighbours, which prevent them to freely deform.

Finally and most important, whether all the cells or only few of them actively participate to the migration process, the most efficient are the ones located at the 
bow of the ellipse. In fact, if we consider each cell as a propulsion-traction system, the propulsion phase is the most important since it determines the direction and the intensity of the migration. Thus, the more a cell is free to elongate during the protrusion phase, the more it will move forward during the contraction phase. This is actually the case of the leading cells, which do not have any frontal neighbours and can therefore protrude as much as they need without any constraint. Therefore, the leading cells may play a fundamental role in collective migration by providing positive feedbacks both in space (direction and intensity of the deformation) and in time (inter-synchronization) (Sect. 1.1) (Sumpter 2006).

\section{Conclusions}

We have proposed here a 2D mechanical model to simulate the collective movement of a cell population, which is represented as a continuum with discrete embedded cells with potential motility behavior (Sect. 2.1). The active strains (i.e. protrusion and contraction) undergone by the single cells during the migration are described through the decomposition of the deformation gradient (Sect. 2.2). Such active deformations are tightly coupled with the adhesion forces necessary to the single cells to move forward (intra-synchronization) (Sect. 2.3.1). Furthermore, the cells must communicate and coordinate their movement in order to be as efficient as possible. Therefore, inter-synchronization between the cells is required (Sect. 2.3.2). The main objective of the paper has been to evaluate the efficiency of the cell population in terms of covered distance and how the stress distribution inside the cohort and the single cells may in turn provide insights regarding such efficiency. In order to achieve this goal, we have explored five different modes of collective migration: (i) chemoattractant migration (Sect. Strain Gradient Signal (or Chemoattractant Migration)), (ii) worm-like migration (Sect. Traveling Wave with Pulse Signal (or Worm-Like Migration)), (iii) tsunami-like migration (Sect. Traveling Wave with Random Unit Step Signal (or Tsunami-Like Migration)), (iv) chemoattractant tsunamilike migration (Sect. Traveling Wave with Gradient Unit Step Signal (or Chemoattractant Tsunami-Like Migration)) and (v) random migration (Sect. Random Signal). Such an analysis has allowed us to investigate the mechanical interplay between the intra- and the inter-synchronization within the cell population (Sect. 3.1) to detect those constraints and forces leading (or not) to an efficient migration.

We have found that the most efficient modes of migration (worm-like migration, tsunami-like migration and chemoattractant tsunami-like migration) are also the ones showing the lowest stresses within the population (Sect. 3.2). Therefore, intersynchronization and randomness are not stand-alone factors of collective cell migration, but they must be coupled. In fact, as also pointed out by Serra-Picamal et al. (2012), cells need to adjust their movement according to the local stress state, which is developed by the movement of their neighbor cells. This results in a mechanotactic signal, which progressively spans the population and stimulates the follower cells. Nevertheless, beside such a mechanotactic signal and in order to have a complete framework of the biological process, one has also to consider the complex molecular signal pathways that may control the acquirement of a motile phenotype of (at least) 
the leading cells. Although here we have only focused on the mechanical aspects of the problem, we are working to improve the present model to take into account these two fundamental aspects.

\section{Appendix}

\section{A.1 Geometry of the cell population}

The cells network $\Omega_{n}$ is described through a characteristic function $h_{n}(\boldsymbol{p})$, which reads

$$
h_{n}(\boldsymbol{p})= \begin{cases}1 & \text { if }\left\|\boldsymbol{p}-2 \cdot r_{c} \cdot \operatorname{round}\left(\boldsymbol{p}_{x}\right) \boldsymbol{i}_{x}-2 \cdot r_{c} \cdot \operatorname{round}\left(\boldsymbol{p}_{y}\right) \boldsymbol{i}_{y}\right\|<r_{c}^{2} \\ 0 & \text { otherwise }\end{cases}
$$

with round being the classical integer function and $\boldsymbol{p}\left(\boldsymbol{p}_{x}, \boldsymbol{p}_{y}\right)$ the initial position of any particle of the system.

Consequently, the ECM domain $\Omega_{\mathrm{ECM}}$ is defined by a characteristic function as follows:

$$
h_{\mathrm{ECM}}(\boldsymbol{p})=1-h_{n}(\boldsymbol{p})
$$

Each cell inside the population is indicated as $c(i, j)$ where the indices $i$ and $j$ vary as follows:

$$
\left\{\begin{array}{l}
1 \leq i \leq N_{c}=i_{\max } \\
1 \leq j \leq n_{c}(i)=n_{c, \max } \sqrt{1-\left(\frac{2 i-1}{N_{c}}\right)^{2}}
\end{array}\right.
$$

with $N_{c}=\frac{L}{r_{c}}$ and $n_{c, \max }=\frac{l}{r_{c}}$ being the number of cells along the two axes of the ellipse (Fig. 1c).

The domain $\Omega_{c_{i, j}}$ of each cell $c(i, j)$ is defined through a characteristic function as follows:

$$
h_{c_{i, j}}(\boldsymbol{p})= \begin{cases}1 & \text { if }\left\|\boldsymbol{p}-\boldsymbol{c}_{i, j}\right\|<r_{c}^{2} \\ 0 & \text { otherwise }\end{cases}
$$

Each cell is equipped with a frontal $\partial \Omega_{s f_{i, j}}$ and a rear $\partial \Omega_{s r_{i, j}}$ adhesion region (Fig. 1d) described by two characteristic functions as

$$
\begin{aligned}
& h_{s f_{i, j}}(\boldsymbol{p})= \begin{cases}1 & \text { if }\left(\boldsymbol{p}-\boldsymbol{c}_{i, j}, \boldsymbol{i}_{x}\right)>l_{f} \\
0 & \text { otherwise }\end{cases} \\
& h_{s r_{i, j}}(\boldsymbol{p})= \begin{cases}1 & \text { if }\left(\boldsymbol{p}-\boldsymbol{c}_{i, j}, \boldsymbol{i}_{x}\right)<l_{r} \\
0 & \text { otherwise }\end{cases}
\end{aligned}
$$

where $(\boldsymbol{a}, \boldsymbol{b})$ defines the scalar product between two vectors, $l_{f}$ and $l_{r}$ are the distances of $c_{i, j}$ from the frontal and rear adhesion surfaces, respectively. 
The ellipse is divided into cell rows $r(i)$ (Fig. 1b), which are numbered, similarly to the single cells, from the stern (left) to the bow (right) of the ellipse ( $1 \leq i \leq N_{c}=$ $i_{\max }$ ) (Fig. 1c) and are defined through a characteristic function as

$$
h_{r_{i}}(\boldsymbol{p})=h_{n}(\boldsymbol{p}) \begin{cases}1 & \text { if }\left(\boldsymbol{p}_{x}-\boldsymbol{c}_{i, j_{x}}\right)<r_{c} \\ 0 & \text { otherwise }\end{cases}
$$

\section{A. 2 Constitutive Model of the Cells}

As mentioned in Sect. 2.2, the behavior of the active and quiescent cells is described through a generalized viscoelastic 2D Maxwell model (Allena 2013; Allena and Aubry 2012). Since the cells within the cohort may undergo large rotations and deformations during their locomotion, a fully non-linear tensorial approach is required.

For the active cells, the Cauchy stress $\sigma_{a}$ is assumed to be the sum of the solid $\left(\sigma_{a, s}\right)$ and the fluid $\left(\sigma_{a, f}\right)$ Cauchy stresses, while the deformation gradient $\boldsymbol{F}_{a}$ is equal to the solid $\left(\boldsymbol{F}_{a, s}\right)$ and the fluid $\left(\boldsymbol{F}_{a, f}\right)$ deformation gradients.

The decomposition of the deformation gradient (Allena et al. 2010; Lubarda 2004) is used to describe the solid deformation tensor $\boldsymbol{F}_{a, s}$ which is then equal to

$$
\boldsymbol{F}_{a, s}=\boldsymbol{F}_{a, s e} \boldsymbol{F}_{a, s a}
$$

where $\boldsymbol{F}_{a, s e}$ is the elastic strain tensor responsible for the stress generation and $\boldsymbol{F}_{a, s a}$ is the active strain tensor responsible for the pulsating movement (protrusioncontraction) of each cell. Similarly, the fluid deformation tensor $\boldsymbol{F}_{a, f}$ is the multiplicative decomposition of the fluid-elastic $\left(\boldsymbol{F}_{a, f e}\right)$ and the fluid-viscoelastic $\left(\boldsymbol{F}_{a, f v}\right)$ gradients.

Both the solid $\sigma_{a, s e}$ and the fluid-elastic $\sigma_{a, f e}$ Cauchy's stresses are given by isotropic hyperelastic models $\bar{\sigma}_{a, s e}$ and $\bar{\sigma}_{a, f e}$, respectively, as

$$
\begin{gathered}
\sigma_{a, s e}=\bar{\sigma}_{a, s e}\left(\boldsymbol{e}_{a, s e}\right) \\
\sigma_{a, f e}=\bar{\sigma}_{a, f e}\left(\boldsymbol{e}_{a, f e}\right)
\end{gathered}
$$

with $\boldsymbol{e}_{a, s e}$ and $\boldsymbol{e}_{a, f e}$ the Euler-Almansi strain tensors for the solid-elastic and the fluid-elastic phases respectively. Additionally, $\sigma_{a, f e}$ has to be expressed in the actual configuration according to the multiplicative decomposition described above. Finally, the strain rate $\dot{\boldsymbol{e}}_{a, f v}$ is related to the deviator part of the fluid-viscous stress $\sigma_{a, f v}^{D}$ as follows:

$$
\dot{\boldsymbol{e}}_{a, f v}=\frac{\sigma_{a, f v}^{D}}{\mu_{a, f v}}
$$

where $\mu_{a, f v}$ is the viscosity.

For the quiescent cells, the same equations can be applied but one has to notice that the solid deformation gradient can now be written as

$$
\boldsymbol{F}_{q, s}=\boldsymbol{F}_{q, s e} \boldsymbol{F}_{q, s a}=\boldsymbol{F}_{q, s e} \boldsymbol{I}
$$

since no active strains take place in these cells (Sect. 2.2). 


\section{A.3 Numerical Implementation of the Constitutive Law}

In this section, we provide the general framework of the numerical approach. For further details, we refer the reader to similar works and applications proposed by Glowinski and Pan (1992) and Vennat et al. (2010).

The cell population is modeled as a continuum (the ellipse). Each one of the three internal regions (active cells $\Omega_{a, k}$, quiescent cells $\Omega_{q, k}$, and ECM $\Omega_{\mathrm{ECM}}$ ) is represented by a level-set function ( $h_{a, k}, h_{q, k}$, and $h_{\mathrm{ECM}}$, respectively). The constitutive behavior of the active and the quiescent cells is described through a $2 \mathrm{D}$ generalized Maxwell model, while the ECM is described by a viscoelastic material. In the finite element formulation, the Cauchy stress $\sigma$ and the viscous strain rate $\dot{\boldsymbol{e}}_{f v}$ are computed at each point $\boldsymbol{p}$ of the continuum taking into account the contributions of the three regions as follows:

$$
\begin{aligned}
& \sigma(\boldsymbol{p})=h_{\mathrm{ECM}}(\boldsymbol{p}) \sigma_{\mathrm{ECM}}(\boldsymbol{p})+\sum h_{a, k}(\boldsymbol{p}) \sigma_{a, k}(\boldsymbol{p})+\sum h_{q, k}(\boldsymbol{p}) \sigma_{q, k}(\boldsymbol{p}) \\
& \dot{\boldsymbol{e}}_{f v}(\boldsymbol{p})=h_{\mathrm{ECM}}(\boldsymbol{p}) \dot{\boldsymbol{e}}_{\mathrm{ECM}_{f v}}(\boldsymbol{p})+\sum h_{a, k}(\boldsymbol{p}) \dot{\boldsymbol{e}}_{a, k_{f v}}(\boldsymbol{p})+\sum h_{q, k}(\boldsymbol{p}) \dot{\boldsymbol{e}}_{q, k_{f v}}(\boldsymbol{p})
\end{aligned}
$$

where $\dot{\boldsymbol{e}}_{\mathrm{ECM}_{f v}}(\boldsymbol{p}), \dot{\boldsymbol{e}}_{a, k_{f v}}(\boldsymbol{p})$, and $\dot{\boldsymbol{e}}_{q, k_{f v}}(\boldsymbol{p})$ are the viscous strain rates for the correspondent domains. Thus, the finite element mesh is not adapted to each sub-region of the continuum, but everything is handled via the level set functions, which allow localizing the mechanical behavior.

Then such a constitutive behavior is implemented in the dynamics equation (Eq. (1)), which involves the aforementioned stress, the displacement acceleration $\boldsymbol{a}$ and the adhesion forces $\boldsymbol{f}_{\text {adh }}$. This equation is first transformed into the weak form of the problem (i.e. principle of the virtual works) and it is then discretized by finite elements. Accordingly, cells/ECM or cells/cells mutual forces are automatically equilibrated in a weak sense although in general, the cell boundaries intersect the finite elements edges. In fact, the level set functions describing the sub-regions of the system are defined independently from the finite element mesh.

\section{A.4 Traveling Wave with Pulse Signal (or Worm-Like Migration)}

In this mode of migration, a traveling wave spans the cell population and successively activate and de-activate the cell rows $r(i)$. Thus, only one row is active at the time and the spatial coordinate $c_{i, j_{x}}$ defining its position changes every migration cycle $T$ (Fig. 2), so that the active cell network $h_{a, 2}(\boldsymbol{p}, t)$ is defined as

$$
h_{a, 2}(\boldsymbol{p}, t)=h_{n}(\boldsymbol{p}) \cdot \begin{cases}1 & \text { if }\left(\left|\boldsymbol{p}_{x}-c_{i, j_{x}}(t)\right|<r_{c}\right) \\ 0 & \text { otherwise }\end{cases}
$$

where $c_{i, j_{x}}(t)$ reads

$$
c_{i, j_{t}}(t)=\left(2 L-r_{c}\right)-2 r_{c} \cdot \operatorname{round}\left(\frac{t}{T}-0.5\right)+2 L \cdot \operatorname{round}\left(\frac{t}{T \cdot N_{c}}-0.5\right)
$$

In this case, also the quiescent domain $h_{q, 2}$ varies in space and time as $h_{q, 2}(\boldsymbol{p}, t)=$ $h_{n}(\boldsymbol{p})-h_{a, 2}(\boldsymbol{p}, t)$. 


\section{A.5 Traveling Wave with Random Unit Step Signal (or Tsunami-Like Migration)}

The characteristic function $h_{a, 3}(\boldsymbol{p}, t)$ defining the active cells network for this mode of migration reads

$$
h_{a, 3}(\boldsymbol{p}, t)=\tau_{i, j} \cdot h_{r_{i}}(\boldsymbol{p}) \cdot h_{s w}(\boldsymbol{p}, t)
$$

where $h_{s w}(\boldsymbol{p}, t)$ describes the progressive wave, which gradually covers the population with a velocity equal to $\frac{2 t}{T}$ and is expressed as

$$
h_{s w}(\boldsymbol{p}, t)= \begin{cases}1 & \text { if }\left(2 L-r_{c}\right)-\boldsymbol{p}_{x}-2 r_{c} \frac{2 t}{T}<0 \\ 0 & \text { otherwise }\end{cases}
$$

Similarly to the previous case, the quiescent cells domain $h_{q, 3} \operatorname{reads} h_{q, 3}(\boldsymbol{p}, t)=$ $h_{n}(\boldsymbol{p})-h_{a, 3}(\boldsymbol{p}, t)$.

\section{References}

Allena, R. (2013). Cell migration with multiple pseudopodia: temporal and spatial sensing models. Bull. Math. Biol., 75, 288-316.

Allena, R., \& Aubry, D. (2012). "Run-and-tumble" or "look-and-run"? A mechanical model to explore the behavior of a migrating amoeboid cell. J. Theor. Biol., 306, 15-31.

Allena, R., Mouronval, A.-S., \& Aubry, D. (2010). Simulation of multiple morphogenetic movements in the Drosophila embryo by a single 3D finite element model. J. Mech. Behav. Biomed. Mater., 3, 313-323.

Anand, R. J., Leaphart, C. L., Mollen, K. P., \& Hackam, D. J. (2007). The role of the intestinal barrier in the pathogenesis of necrotizing enterocolitis. Shock, 27, 124-133.

Arciero, J. C., Mi, Q., Branca, M. F., Hackam, D. J., \& Swigon, D. (2011). Continuum model of collective cell migration in wound healing and colony expansion. Biophys. J., 100, 535-543.

Bausch, A. R., Möller, W., \& Sackmann, E. (1999). Measurement of local viscoelasticity and forces in living cells by magnetic tweezers. Biophys. J., 76, 573-579.

Borisy, G. G., \& Svitkina, T. M. (2000). Acting machinery: pushing the envelope. Curr. Opin. Cell Biol., 12, 104-112.

Carlier, M. F., \& Pantaloni, D. (1997). Control of actin dynamics in cell motility. J. Mol. Biol., 269, 459467.

Carlsson, A. E., \& Sept, D. (2008). Mathematical modeling of cell migration. Methods Cell Biol., 84, 911-937.

Chen, X., \& Friedman, A. (2000). A free boundary problem arising in a model of wound healing. SIAM J. Math. Anal., 32, 778.

Condeelis, J. (1993). Life at the leading edge: the formation of cell protrusions. Annu. Rev. Cell Biol., 9, 411-444.

Dong, C., Slattery, M. J., Rank, B. M., \& You, J. (2002). In vitro characterization and micromechanics of tumor cell chemotactic protrusion, locomotion, and extravasation. Ann. Biomed. Eng., 30, 344-355.

Drury, J. L., \& Dembo, M. (2001). Aspiration of human neutrophils: effects of shear thinning and cortical dissipation. Biophys. J., 81, 3166-3177.

Farooqui, R., \& Fenteany, G. (2005). Multiple rows of cells behind an epithelial wound edge extend cryptic lamellipodia to collectively drive cell-sheet movement. J. Cell Sci., 118, 51-63.

Fenteany, G., Janmey, P. A., \& Stossel, T. P. (2000). Signaling pathways and cell mechanics involved in wound closure by epithelial cell sheets. Curr. Biol., 10, 831-838.

Flaherty, B., McGarry, J. P., \& McHugh, P. E. (2007). Mathematical models of cell motility. Cell Biochem. Biophys., 49, 14-28.

Friedl, P., \& Gilmour, D. (2009). Collective cell migration in morphogenesis, regeneration and cancer. Nat. Rev. Mol. Cell Biol., 10, 445-457. 
Friedl, P., \& Wolf, K. (2010). Plasticity of cell migration: a multiscale tuning model. J. Cell Biol., 188, 11-19.

Fukui, Y., Uyeda, T. Q. P., Kitayama, C., \& Inoué, S. (2000). How well can an amoeba climb? Proc. Natl. Acad. Sci. USA, 97, 10020-10025.

Gaffney, E. A., Maini, P. K., McCaig, C. D., Zhao, M., \& Forrester, J. V. (1999). Modelling corneal epithelial wound closure in the presence of physiological electric fields via a moving boundary formalism. IMA J. Math. Appl. Med. Biol., 16, 369-393.

Giannone, G., et al. (2007). Lamellipodial actin mechanically links myosin activity with adhesion-site formation. Cell, 128, 561-575.

Glowinski, R., \& Pan, T.-W. (1992). Error estimates for fictitious domain/penalty/finite element methods. Calcolo, 29, 125-141.

Gracheva, M. E., \& Othmer, H. G. (2004). A continuum model of motility in ameboid cells. Bull. Math. Biol., 66, 167-193.

Graner, F., \& Glazier, J. A. (1992). Simulation of biological cell sorting using a two-dimensional extended Potts model. Phys. Rev. Lett., 69, 2013-2016.

Holzapfel, G. A. (2000). Nonlinear solid mechanics: a continuum approach for engineering (1st ed.). New York: Wiley.

Ilina, O., \& Friedl, P. (2009). Mechanisms of collective cell migration at a glance. J. Cell Sci., 122, 32033208.

Laurent, V. M., et al. (2005). Gradient of rigidity in the lamellipodia of migrating cells revealed by atomic force microscopy. Biophys. J., 89, 667-675.

Lubarda, V. (2004). Constitutive theories based on the multiplicative decomposition of deformation gradient: thermoelasticity, elastoplasticity, and biomechanics. Appl. Mech. Rev., 57, 95-109.

Maini, P. K., McElwain, D. L. S., \& Leavesley, D. I. (2004). Traveling wave model to interpret a woundhealing cell migration assay for human peritoneal mesothelial cells. Tissue Eng., 10, 475-482.

McLennan, R., et al. (2012). Multiscale mechanisms of cell migration during development: theory and experiment. Development. Available at: http://dev.biologists.org/content/early/2012/07/04/dev.081471 [Accessed April 27, 2013].

Meili, R., Alonso-Latorre, B., del Alamo, J. C., Firtel, R. A., \& Lasheras, J. C. (2010). Myosin II is essential for the spatiotemporal organization of traction forces during cell motility. Mol. Biol. Cell, $21,405-417$.

Mogilner, A., \& Rubinstein, B. (2005). The physics of filopodial protrusion. Biophys. J., 89, 782-795.

Murray, J. D. (2003). Mathematical biology II: spatial models and biomedical applications. Berlin: Springer.

Phillipson, M., et al. (2006). Intraluminal crawling of neutrophils to emigration sites: a molecularly distinct process from adhesion in the recruitment cascade. J. Exp. Med., 203, 2569-2575.

Rubinstein, B., Jacobson, K., \& Mogilner, A. (2005). Multiscale two-dimensional modeling of a motile simple-shaped cell. Multiscale Model. Simul., 3, 413-439.

Sakamoto, Y., Prudhomme, S., \& Zaman, M. H. (2011). Viscoelastic gel-strip model for the simulation of migrating cells. Ann. Biomed. Eng., 39, 2735-2749.

Serra-Picamal, X., et al. (2012). Mechanical waves during tissue expansion. Nat. Phys., 8, 628-634.

Sheetz, M. P., Felsenfeld, D., Galbraith, C. G., \& Choquet, D. (1999). Cell migration as a five-step cycle. Biochem. Soc. Symp., 65, 233-243.

Sherratt, J. A., \& Murray, J. D. (1990). Models of epidermal wound healing. Proc. - Royal Soc., Biol. Sci., 241, 29-36.

Sherratt, J. A., \& Murray, J. D. (1991). Mathematical analysis of a basic model for epidermal wound healing. J. Math. Biol., 29, 389-404.

Soofi, S. S., Last, J. A., Liliensiek, S. J., Nealey, P. F., \& Murphy, C. J. (2009). The elastic modulus of Matrigel $^{\mathrm{TM}}$ as determined by atomic force microscopy. J. Struct. Biol., 167, 216-219.

Sumpter, D. J. (2006). The principles of collective animal behaviour. Philos. Trans. R. Soc. Lond. B, Biol. Sci., 361, 5-22.

Szabo, B., et al. (2006). Phase transition in the collective migration of tissue cells: experiment and model. arXiv:q-bio/0611045. Available at: http://arxiv.org/abs/q-bio/0611045. Accessed April 27, 2013.

Taber, L. A. (2004). Nonlinear theory of elasticity: applications in biomechanics. Singapore: World Scientific.

Taber, L. A., Shi, Y., Yang, L., \& Bayly, P. V. (2011). A poroelastic model for cell crawling including mechanical coupling between cytoskeletal contraction and actin polymerization. J. Mech. Mater. Struct., 6, 569-589. 
Tambe, D. T., et al. (2011). Collective cell guidance by cooperative intercellular forces. Nat. Mater., 10, 469-475.

Theriot, J. A., \& Mitchison, T. J. (1991). Actin microfilament dynamics in locomoting cells. Nature, 352, 126-131. Published online: 11 July 1991. doi:101038/352126a0.

Trepat, X., et al. (2009). Physical forces during collective cell migration. Nat. Phys., 5, 426-430.

Vedel, S., Tay, S., Johnston, D. M., Bruus, H., \& Quake, S. R. (2013). Migration of cells in a social context. Proc. Natl. Acad. Sci. USA, 110, 129-134.

Vennat, E., Aubry, D., \& Degrange, M. (2010). Collagen fiber network infiltration: permeability and capillary infiltration. Transp. Porous Media, 84, 717-733.

Vicsek, T., Czirók, A., Ben-Jacob, E., Cohen, I., \& Shochet, O. (1995). Novel type of phase transition in a system of self-driven particles. Phys. Rev. Lett., 75, 1226-1229.

Wagh, A. A., et al. (2008). Localized elasticity measured in epithelial cells migrating at a wound edge using atomic force microscopy. Am. J. Physiol., Lung Cell. Mol. Physiol., 295, L54-60.

Weijer, C. J. (2009). Collective cell migration in development. J. Cell Sci., 122, 3215-3223.

Xue, C., Friedman, A., \& Sen, C. K. (2009). A mathematical model of ischemic cutaneous wounds. Proc. Natl. Acad. Sci. USA, 106, 16782-16787.

Yamao, M., Naoki, H., \& Ishii, S. (2011). Multi-cellular logistics of collective cell migration. PLoS ONE 6 , e27950. 